THE ACTIVE MUSICAL ROOM

This is the pre-copyedited version of a paper that has been recently accepted in the JOURNAL OF RESEARCH IN MUSIC EDUCATION, published online in 2020. Please do not quote or cite this version

\title{
The Active Musical Room: Fostering sensorimotor discovery and musical creativity in toddlers
}

\author{
Alicia Peñalba ${ }^{1}$, Lucio Martínez-Álvarez ${ }^{2}$ \& Andrea Schiavio ${ }^{3}$ \\ ${ }^{1}$ Music Area, University of Valladolid, ES. Orcid: https://orcid.org/0000-0002-5725-0639. \\ Faculty of Education, Avenida de Madrid, 50, Palencia 34004. alicia.penalba@uva.es \\ ${ }^{2}$ Body Expression department. University of Valladolid, ES. Orcid: https://orcid.org/0000-0002-6797-6476 \\ ${ }^{3}$ Centre for Systematic Musicology, University of Graz. Orcid: https://orcid.org/0000-0001-8109-9185
}




\begin{abstract}
In the current study, we investigate the implementation of a musical workshop in an early childhood education setting. The workshop is based on a shared space for musical creativity (the Active Musical Room) comprising six different musically relevant objects, which toddlers were free to explore and play with. Inspired by Delalande's Pedagogie musicale d'éveil, the workshop was facilitated by a teacher, who developed strategies to help the toddlers' musical engagement. Data sources for this case study included semi-structured interviews with the teacher and school principal, video recordings of each session, fieldnotes and observations made by non-participant observers, and questionnaires completed by parents of the toddlers. Categories concerning three interrelated dimensions of interest emerged from our analyses: the decisions of the teacher, the affordances of the objects in the room, and the creative potential of each toddler. While generalizations cannot be proposed given the nature of the study, our results point to the recursive interplay between the exploratory drive of the toddlers, their sensorimotor ability, and the constraints afforded by the environment in which they are situated (i.e., teachers, objects).
\end{abstract}

Keywords: Musical Development; Musical Creativity; Music Education; Embodied Cognition; Early Infancy 
THE ACTIVE MUSICAL ROOM

Scholarship regarding early childhood musical experience has increased in recent years, stimulating important research and theory at the crossroads of the humanities, sciences, and practice-oriented disciplines (e.g., Deliège \& Sloboda, 1996; Hargreaves, 1986; McPherson, 2006; Young, 2003). Researching the complex social, behavioral, emotional, and cognitive dynamics involved in musical development can help provide richer insights into a variety of issues associated with the early acquisition of sensorimotor and musical skills (e.g., Addessi et al., 2015; Hargreaves \& Lamont, 2017; Phillips-Silver \& Trainor, 2005), the flourishing of one's musical identity and culture (e.g., Soley \& Hannon, 2010; Tafuri, 2017; Trainor et al., 2012), and the wide range of activities that can facilitate the emergence of music-specific behaviors (e.g., Gerson et al., 2015; Gratier, 2003; Krueger, 2013; Schiavio et al., 2017; Trevarthen, 1999).

Among others, Bamberger argued that "musical development is enhanced by continuously evolving interactions among multiple organizing constraints along with the disequilibrium and sensitivity to growing complexity that these entanglements entrain" (Bamberger, 2006, p. 71). As such, it is of great importance to study how and why different environmental constraints could shape the toddlers' transformative experience of music ${ }^{1}$. It could be particularly useful to examine the embodied and socially-situated dynamics involved in children's musical experiences, for example: what affordances ${ }^{2}$ of the environment can act as a constraint, and how can these be effectively integrated in one's musical learning experience? How can bodily and socially meaningful resources take part in the early musical development? Not only can research aimed at

\footnotetext{
${ }^{1}$ In this article we use the term infant to indicate human beings below 12 months of age. The term toddler refers to those ranging from 12 to 36 months of age, whereas the term children is used for older ones.

2 "Affordances", according to ecological psychology (Gibson, 1979), refer to the action possibilities of an object of the environment. Instead of considering them fixed, or pre-given properties, they depend on the biological complexity and motor expertise of the living system that engages with the object (see also Clarke, 2005).
} 


\section{THE ACTIVE MUSICAL ROOM}

answering these and similar questions increase our understanding of musical development in general; it can also improve existing pedagogical settings, and stimulate the emergence of novel creative musical activities that more decisively depend on the complex interplay between children and the environments in which they are situated.

In the current paper we engage with both of these lines of inquiry, exploring the rich individual, social, and material aspects that can enhance musical development when the creative potential of young learners is prioritized. We hope to provide novel conceptual tools that can be used to better describe the early acquisition and optimization of musical skills. We also address educational issues that emerge in a specific pedagogical context with the aim of developing insights that can help educators (a) better meet the toddlers' individual and social needs, (b) foster their musical creativity, and (c) accommodate their drive to explore their (musical) environment. To these ends, we report on an exploratory study based on the "Active Musical Room" (AMR) project, a project housed in a local school for toddlers and young children in the city of Palencia (Spain). The AMR project involved the creation of a shared musical space within a broader educational context, which pupils were free to explore twice a week over a period of two months.

\section{Early Music Education, Creative Pedagogies, and the Primacy of Action}

Human infants display a fascinating predisposition for music (Malloch \& Trevarthen, 2018; Trehub, 2003a, 2003b). As they develop and improve their sensitivity toward the world and its properties, they become increasingly interested in music-related activities such as listening (Zentner \& Kagan, 1996), music-making (Delalande, 2009), and dancing in rudimentary ways (Zentner \& Eerola, 2010). In doing so, they often explore their material environment in various ways; discovering objects, sounds, and the corresponding motor configurations that emerge in the 
THE ACTIVE MUSICAL ROOM

process (i.e., the movements that generate those sounds) (Schiavio et al., 2017). This may lead infants to manipulate objects, play with their sonic properties, and create original sensorimotor patterns that can inspire novel musical experiences and discoveries. The early manifestations of this creative potential has drawn the attention of a number of scholars and pedagogues interested in describing how infants and toddlers develop their own musicality, and how novel pedagogical tools can be offered to stimulate and enhance their autonomous musical experiences (Delalande \& Cornara, 2010; Gordon, 1993, 1997).

Some scholars have specifically focused on the rich variety of modes of engagement that infants, toddlers, and older children develop with instruments and sound-producing objects (e.g., Céleste et al., 1982; Filippa, 2009). Other researchers have contributed innovative perspectives on (a) music therapy and improvisation with infants (Malloch et al., 2012; Filippa et al., 2020), (b) improvisation among preschoolers (Flohr, 1985; Gratier \& Magnier, 2012), and (c) meaningful musical experiences in Pillsbury and Reggio Emilia settings (Bond, 2015a, 2015b, 2018; Moorhead \& Pond, 1978). In addition, other scholars have developed critical perspectives on musical activities and experiences in early childhood (Dansereau, 2015; Young, 2018), highlighting the functional role that music-like behaviors play in driving different world-revealing processes (van der Schyff et al., 2016; 2018).

These broad cross-contextual outcomes may in part explain why the implementations of different creative pedagogies (in which children are often conceived of as composers) can include the development of interdisciplinary projects involving other school subjects such as natural sciences, language, and social sciences (Dennis, 1975; Paynter \& Aston, 1970), as well as more specific interventions based on musical experimentation, improvisation, and free play (Delalande et al., 2001; Schafer, 1969; 1976). Consider for example Delalande's Pedagogie musicale d'éveil 


\section{THE ACTIVE MUSICAL ROOM}

(Delalande et al., 2001), a pedagogical proposal that advocates a novel synthesis among physical materials (i.e., the musical objects of the environment), actions (i.e., the motor configurations emerging when exploring the objects), and sounds (i.e., the outcomes of similar exploratory endeavors). With a core interest in stimulating early musical creativity through action and discovery, Delalande's approach was influenced by the Groupe Recherches Musicales (GRM)funded by Pierre Schaeffer. It starts with systematic observations of the spontaneous musical behaviors of infants and toddlers of different ages (Delalande \& Cornara, 2010).

Inspired by early work by Piaget as well as by the notion of sound objects proposed by Schaeffer (1966), Delalande argues that human beings have an innate drive for discovering and actively engaging with the sonic opportunities offered by their niche and for developing meaningful sound-based interactions with the world starting at birth. Indeed, infants and toddlers can be observed going through three different phases in which these characteristics (e.g., active engagement, discovery, sound manipulation) play a key role (Delalande \& Cornara, 2010, p. 259). A first phase consists of exploration - the development of increasingly sophisticated patterns of motor activity to engage with the regularities in the environment. Here, sensorimotor skills, as well as basic understandings of how different objects may sonically respond to diverse actions are acquired. Secondly, the semantic phase describes how toddlers can become familiar with new sounds through (musical) actions based on repetition and variation. Finally, in the creative phase, children use the discovered sounds to create an original piece of music with its own rules and styles (Delalande et al., 2001, p. 12).

To better capture the complexity of the relationship between sounds, materials, and motor activity, Delalande classifies sounding objects in light of their different pedagogical value, including their diverse affordative properties. The distinctive qualities of the various objects that 
THE ACTIVE MUSICAL ROOM

toddlers can musically interact with can be captured through the following five categories (Delalande et al., 2001, pp. 91-99):

1. Transportability. Can the object be moved?

2. Raw materials. What is the object made of?

3. Brief vs. sustained sound qualities. Does the object create a short or a sustained sound?

4. Controlled vs. aleatory interaction. What is the level of accuracy in controlling the object? (e.g., aleatory, half controlled, controlled)

5. Ways of interaction. How can the object produce sounds? (hitting, shaking, grasping, etc.)

These categories describe the various proposals the teacher should offer so that objects can be manipulated, controlled, and used to generate sounds. In doing so, they point to the primacy of action. If a good way to look at musical development is to explore material engagement and sensorimotor activity, then we may approach this phenomenon from the perspective of a framework that sees action as the main driver of mental life and experience. We refer here to an approach known as Embodied Cognition (e.g., Gallagher, 2005; Johnson, 2007). With its central idea being that cognition strongly depends on the patterns of action developed by a brain-body system within a contingent milieu, this paradigm may better capture how objects, actions, and living systems recursively interact (e.g., Chemero, 2009; Thompson, 2007; Varela et al.,1991).

As briefly mentioned above, a notion of particular relevance for such an approach is that of affordance (Gibson, 1979). Understood as the set of motor possibilities offered by an object of 


\section{THE ACTIVE MUSICAL ROOM}

the environment to an interacting organism, the term refers to the complex interplay between living systems and their niche and can be used when describing optimal patterns of activity from which a meaningful interaction emerges. In the context of our study, we adopt the notion of affordance to help us negotiate between two important dimensions that are pedagogically relevant, here reported as the following claims: (i) what toddlers primarily perceive when they interact with materials are their affordances, and not their qualities (like aesthetic qualities). This means that toddlers best learn about the world and its properties via multiple series of action-perception coupling rather than through observation; and (ii) the perception of affordances involves a direct relationship with the perceiver's own actions. It has been argued that perceiving the world means to perceive the self through proprioception (Peñalba, 2011), a recursive process which may provide the basis for the development of higher-order consciousness. Insights inspired by this scholarship have recently emerged in music research, provoking discussions on the role of body and action for musical meaning, experience, and development (Cox, 2017; Leman, 2007; Loaiza, 2016; Schiavio \& van der Schyff, 2016, 2018).

The role and key features of musical affordances, for example, is being increasingly discussed (e.g., Clarke, 2005; Menin \& Schiavio, 2012). In a similar vein, a recent paper by Einarsson and Ziemke (2017), advanced the thesis that a fruitful understanding of musical affordances should also include the sociocultural dimension that permeates one's (musical) experience and situatedness. According to Einarsson and Ziemke, this can help elucidate several music-related processes involved in the creation of novel material that are often theorized as intrapersonal and disembodied. This sociocultural dimension emerges in our study via the ecological setting where the study takes place, which involves the school's pedagogical principles as well as the different social interactions between toddlers, between toddlers and the teacher, and between 
THE ACTIVE MUSICAL ROOM

toddlers and their parents. In our study, we attempt to bring together the centrality of action advocated by embodied cognition and the spontaneous engagement central to research on early musical development discussed above. The research questions guiding our study were as follows: In what sense can the relationship between actions and objects take part in and enhance musical learning? What objects are preferred, and how can they shape one's learning trajectory?

\section{Method}

Our study is based on the creation and implementation of a musical space - the Active Musical Room (AMR) — placed in an existing educational setting, a school named Casa Activa (CA). Each session within the AMR included the constant supervision and active participation of a teacher, who encouraged the pupils (without leading or directing them) to interact creatively with different sound-producing objects. Being organized as a case study (Stake, 1995), our approach is holistic, contextual, participatory, and empathetic: it aims to focus on the perspective of the studied population rather than those of the observers. As such, we mainly describe rather than explain how the socio-educational phenomenon we address unfolds. Finally, the design of this research was emergent, that is, it was built up as the research progressed. We triangulated data based on (a) interviews with the teacher who supervised the sessions, as well as with the school's principal; (b) direct observations of the musical activities occurring in the AMR, with the support of the teacher, who also commented on them during or after every session, and (c) questionnaires completed by the families of the toddlers. As we will see, three interrelated categories emerged from our open coding analysis: the range of decisions taken by the teacher within the AMR, the constraints and 
THE ACTIVE MUSICAL ROOM

affordances of the objects in the AMR, and the emergence of creative patterns of (inter)action by the toddlers during AMR sessions.

\section{The Educational setting}

\section{Casa Activa (CA)}

CA is a school governed by principles of active pedagogies such as Montessori, Pickler, and Accouturier. It aims to create a safe shared environment for a total of 22 pupils between 15 and 36 months old. CA has three teachers and is located in a one-floor house in Palencia, Spain. Many of its rooms serve multiple purposes, that is, throughout the day, rooms can be modified to facilitate a variety of learning experiences, many of them in the form of workshops which toddlers are free to participate in. An $11 \mathrm{~m}^{2}$ room was assigned as the physical place for the AMR.

\section{The Active Musical Room (AMR)}

The AMR is a musical space where a workshop based on the presentation of, and active engagement with, different objects is offered (see Figure 1). The AMR workshop discussed in this paper ran for a total of 15, 1-hour sessions from October to November 2018 and aimed to foster exploratory behaviors and musical creativity in a social environment with the support of one teacher. The teacher was present during all sessions; she accompanied the toddlers in the AMR but did not give them any direction regarding what to explore or how. As with the other workshops in CA, toddlers were free to enter the AMR and interact with objects spontaneously.

A total of six complex objects were selected for the workshop according to the Delalande's aforementioned five categories (see Table 1) and the pedagogical principles of CA, which were 
THE ACTIVE MUSICAL ROOM

influenced by Reggio Emilia (e.g., use of natural objects; displays of objects ready to use; aesthetically pleasing objects; participation of toddlers at their will; role of teachers as facilitators) (see Figure 1). The following objects were selected: scraper (wooden tablecloth composed of sheets arranged horizontally); nuts on glass (walnuts in a raffia bag over glass cup); beans in tambourine; bamboo leaves (bamboo leaves on corrugated wooden table); tiles ${ }^{3}$; and curtain (pendant tubes made of cylindrical metal, bamboo rods, and steel plates). The room only contained these objects and no other instruments or objects were used in the room during the implementation of the program.

\section{Participants}

\section{Toddlers}

Twenty-two toddlers (9 females, 13 males), aged 15-36 months (median age 21.14 months) participated in the study. ${ }^{4}$ Two of them had special education needs (Pablo was diagnosed with Down Syndrome; Daniel had a rare condition that involves the absence of chromosome 18). Thirteen toddlers were new to the school and were taking part in an adaptation period when the study was conducted ${ }^{5}$. All families signed provided informed consent to participate in the study. All procedures were carried out in accordance with the statements of the Declaration of Helsinki. Participants and families were not monetarily compensated for their involvement in the study.

\footnotetext{
${ }^{3}$ These are roof tiles made of ceramic, which can oscillate, places in the floor.

${ }^{4}$ All names of toddlers are pseudonyms.

${ }^{5}$ The adaptation period consists of a limited but flexible period of time - approximately one month - in which toddlers are helped through the separation from their families. Among other initiatives, the following are taken: family members are allowed to stay for a while at the entrance to the school; toddlers stay less time than usual until they adapt; there are fewer toddlers in the center so that teachers can devote more attention to them. The time needed by each toddler is different and each receives individualized help.
} 


\section{Teacher and Principal}

One CA teacher (female, aged 32) volunteered to implement the AMR. The teacher and the school's principal (male, aged 39) were both involved in the design of the AMR. This included participating in preliminary meetings, offering feedback to the researchers' proposal, and discussing the results of the study.

\section{Observers}

The first two authors of this paper (AP and LM), along with a research assistant, collected video recordings and fieldnotes. All acted as non-participant observers.

\section{Data Collection}

\section{Observations}

All 15 of the AMR workshop sessions were video recorded and two out of three observers collected field notes by systematic observation through a field diary at all sessions (Guest et al., 2013). The field diary consisted of thick description (i.e., detailed narratives or vignettes explaining situations and their background context) of the teacher's behaviour and the toddlers' interactions with the objects (in light of Delalande's categories) as well as other relevant insights (Denzin, 2001). Additionally, an observation template was completed for each session by consulting the video recording. The template was developed to organize information gathered from videos and field diaries into labels such as participant, object's uses (gestures), space use (location), teacher's guidance (gestures or words), and social interactions (peers and teacher-toddler). 
THE ACTIVE MUSICAL ROOM

\section{Interviews}

Two semi-structured interviews with the teacher were conducted by the first and second author. The first one took place after the end of data collection in order to gather information about the program as a whole. It addressed the teacher's general impressions of the program, comments on specific toddlers, her decisions for how to guide students (for exploration, rules, and affectivity), the objects and their possible uses, social interactions, Delalande's phases, and inclusiveness. After the interview was transcribed verbatim and shared with her, a second interview was conducted. The purpose of the second interview was to clarify some of the ideas and topics emerged from the previous one, which included attention to individual and collective needs, as well as strategies for ensuring all toddlers' emotional security. A third interview was then conducted with the principal. The main results of the study were discussed with him to receive his feedback and for triangulation purposes.

\section{Questionnaires}

An open-ended questionnaire was designed to explore the toddlers' daily musical engagement at home, their interest and autonomous exploratory activities, the various (behavioral, musical, affective, etc.) changes observed by the parents after the AMR experience, and the musical backgrounds of parents and relatives. Questionnaires were sent by email (as suggested by the school) after the end of the final AMR session. Seventeen questionnaires from 18 families out of the 22 pupils (two of them, twins) were returned ${ }^{6}$. Data from questionnaires were used for triangulating the toddlers` observed behavior within the AMR.

\footnotetext{
${ }^{6}$ All data can be accessed by contacting corresponding author.
} 
THE ACTIVE MUSICAL ROOM

\section{Data Analysis}

The verbatim transcriptions of the three interviews and the other data were labeled and uploaded into an atlas.ti 8.0 project (Table 2). Open coding (Strauss \& Corbin, 1990) was carried out for the field diaries (FD), observation templates (OT), teacher's interviews (IT), principal's interview (IP), video recordings (VR), and parents' questionnaires $(\mathrm{QP})$. The codes were grouped into higherorder categories and linked to the various topics and research questions proposed (see Table 3). These included:

1. Teacher's perspectives: behaviour (teacher's concerns and actions regarding freedom and limits), affectivity (teacher's decisions regarding affectivity and safety concerns, particularly for those in the adaptation period), and experimentation (teacher's encouragement of exploration of objects and creative process).

2. Objects' affordances: physical features (features of objects that attract toddlers), objects in context (practicality of the use of objects within the specific context), and engagement (gestural and sonic possibilities of each object).

3. Toddlers' perspectives: process (Delalande's three phases of sound experimentation: sensorimotor, semantic, and creative), inclusion (presence of others, participation, and progress within AMR), and social interaction (observation of others, interaction with others, and collaborative play).

\section{Results}


THE ACTIVE MUSICAL ROOM

Results are presented according to the categories that emerged from analysis. Quotations are included to illustrate the complexity and richness obtained from the data. When appropriate for triangulation, the source is indicated in brackets along with the aforementioned codes.

\section{The Teacher's Perspective}

The teacher dealt with many different issues when facilitating the musical experiences that emerged from the interactions between toddlers and the objects in the AMR, including how to adapt the activities of the workshop to the main pedagogical principles of the CA (freedom and individual respect), the affective needs of each toddler (particularly those who were new to the school and just becoming acclimated to it), and the requirements of the workshop (i.e., a focus on exploration and participants' creative processes).

\section{Behavior: Freedom Versus Limits}

Similar to other CA workshops, the AMR is based on the idea that toddlers should be able to participate freely (IT.1). This explains why the presence of toddlers in the workshops varied from two (OT.1) to six (OT.10) at any given point in time. Some toddlers entered many times, such as Pablo (8 times) or Antonio (10 times), whereas others took part in the workshop only a few times (Alejandro, Elsa, Sara, María, and David entered only once). The school's principal explained that this variety of engagement was a function of individual preferences as well as the maturity level of each toddler. He claimed that if the program were longer, then all toddlers would have participated more often (IP.1). Individual differences among the toddlers also shaped the teacher's decisions as the workshop unfolded. Sometimes there were toddlers who could not behave properly, and even endangered the physical integrity of others. The teacher had to act and establish 


\section{THE ACTIVE MUSICAL ROOM}

limits that were flexible enough to suit each toddler when dealing with these kinds of problems. In the teacher's words:

I do not plan "today I'm going to let the room go wild". [The process] is more emotional than that. When Aida came in, I needed the beans to be in the tambourine. Because besides Aida there is Pablo, and he might slip [...]. With some [toddlers] I see more possibilities for experimentation if everything is tidy (TI.2).

Minimal risks were considered opportunities for learning and were often used for pedagogical purposes (IP.1). Strong behavioral intervention, indeed, was not always the best solution since they would require the full attention of the teacher (VR.14) and also limit each toddler's freedom to explore. Therefore, the teacher had to continuously negotiate between setting limitations and allowing individual freedom, making sure the latter expanded the needs, desires, and curiosity of the toddlers.

\section{Affectivity}

The teacher also had to deal with issues that emerged due to new students needing to acclimate to the school. During these time periods, the teacher had to balance the needs of toddlers who required extra emotional support with the exploratory drive of the toddlers who already had acclimated to the school. Consider the following example involving Tomás (who was in the acclimation period) and Daniel (who had already acclimated): Tomás's parents said he usually needed the teacher to be nearby (QP.1), which limited the attention the teacher could devote to Daniel when they were both together. As the teacher reported: 
THE ACTIVE MUSICAL ROOM

I remember Tomás the first day. He was stuck and needed me [FD.3] [...] [Daniel] has always been apart [...]. Maybe he would have needed more adult intervention. If he [Daniel] doesn't get attention, he remains observing instead of acting (IT.2).

Except for one occasion (session 9) in which he was very active, Daniel observed more than explored (FD.1-15). The example shows that the teacher prioritized affective needs; if a toddler did not feel safe, he or she could not freely engage with the objects and discover their sonic opportunities.

\section{Experimentation}

One idea central to Delalande's proposal is that different objects afford different possibilities of musical engagement and sensorimotor exploration. Therefore, one of the teacher's missions was to foster and facilitate this exploratory need. The teacher usually waited for each toddler to approach each object before encouraging active exploration of the objects and their sonic affordances. This was not easy, as each toddler had unique personal tendencies and different degrees of curiosity. Some toddlers, for instance, were shy and needed help from the teacher to engage with the objects. The teacher, if asked to do so, might have also handed the objects directly to them (this was the case with Tomás, Luis, Daniel, Pablo). In addition, some toddlers needed limits to ensure safety (Aida, Pedro), whereas others required observation first (Antonio). These different ways of interaction, it should be noted, were not fixed and static, instead, they changed over time as relationships were formed and affordances were experienced. Consider for example, 


\section{THE ACTIVE MUSICAL ROOM}

Luis, who initially needed more emotional support than others, but eventually demonstrated highly independent behavior in later sessions (OT.14).

The teacher generally described the process of facilitating experimentation as a game that she guided without "talking too much" (IT.1). Therefore, the teacher's ways of fostering exploration and engagement did not start with predefined notions or models of what to do; rather, they had to be fluid enough to meet the diverse individual needs that characterized the personal musical identity and sensorimotor development of each toddler. As such, the guidance from the teacher changed over time as the toddlers developed and the workshop progressed.

\section{Objects' Affordances}

Three categories emerged within the higher-order category objects' affordances: physical features, objects in context, and engagement. In this section, findings will be reported according to the affordative potential of each object in the AMR. In general, toddlers were interested in some objects more than others and they maintained their interests throughout the sessions. Only when many sonic properties of an object were explored in detail, did the toddlers feel ready to explore a new one (OT.1-15). This behavior, which prioritizes meaningful engagement over superficial encounters, was seen by the principal as something that also occurs within other workshops in the CA (e.g., not just the AMR) (IP.1).

\section{Beans in Tambourine}

Beans appear to have been the most attractive objects for our participants, since someone was exploring them in every session (FD.1-15). The teacher discussed the musical possibilities of the beans, but also the challenges they produced. She reported: "I doubt that at home they have 
THE ACTIVE MUSICAL ROOM

experimented with beans [although they could have done so with other objects]" (IT.2). Other uses of the beans were documented in the observation templates: these included stirring them with a drumstick (OT.1), pouring them from one container to another (OT.4), bouncing them into the tambourine (OT.5), rubbing them against different surfaces (OT.6), and shaking them while holding them in their hands (OT.8), among others. Although the beans inspired many different forms of engagement, they were also considered the least practical; and indeed, for the teacher, they often represented a source of anxiety (e.g., beans might invade the space of other objects). Sometimes beans were thrown onto the floor, which inspired new ways to play — such as pretending to swim - to be developed and collaboratively enacted (Daniel FD.11 or Lucas and Pablo FD.12). Finally, the beans allowed hybrid uses of objects. Toddlers used them with the glass bowl, tiles, curtain, or bamboo leaves. Also, the floor was used as a resonance space to sweep, throw, or bounce them. As such, although they also presented limitations due to endangerment and loss of space limits, beans seemed to have the greatest affordative possibilities.

\section{Nuts in Glass Bowl}

At the beginning, nuts were not attractive for our toddlers. As the program progressed, the teacher began to use them to (pretend to) caress the younger ones and create affective bonds. Interestingly, in later sessions (FD.6) they become an object almost as attractive as the beans, and the teacher valued them as one of the most interesting objects because of their sound-gestural affordances (TI.1). The nuts provided possibilities for both individual musical play and social interaction. Examples of individual play included using nuts in combination with other objects or using them alone. Both occurrences were observed in Aida, who often stirred the nuts in the bowl (FD.10), Daniel, who put the nuts in the bowl and shook them (FD.9), Claudia and Rubén, who used the 


\section{THE ACTIVE MUSICAL ROOM}

tambourine in combination with the nuts to create strong repetitive sounds (FD.8; FD.13), Pedro, who used the tile as a container for nuts (FD.8), Manuel, who hit the nuts together (FD.14), Clara, who twisted the nuts in the floor (FD.15). and Luis, who put the nuts in the bag (FD.13). The use of nuts also provided a nice opportunity for toddlers to play together; this was the case for Clara and Lucas (FD.9), where Pedro was seen holding the bowl for Clara (collaborative playing), Clara and Sara (FD.9), where Clara used the object exactly as Sara did (imitation), Manuel and Sara (FD.14) and Clara and Héctor (FD.15), where in both cases they collaboratively made sounds through joint performance in different ways (e.g., they both used the nuts and tambourine together for percussive sounds).

\section{Tiles}

The teacher believed the tiles were the objects having the least affordances for toddlers of this age (TI.1). The tiles were heavy and could not be lifted; and oscillatory movement was difficult for toddlers to achieve with them. Only Antonio and Pedro were able to make the tiles oscillate (FD.10). Sometimes, tiles were used as a container or as a percussion instrument with drumsticks (Pedro, FD.10). Tiles are considered 'object-space' in Delalande's first category (e.g., they can be attached to a physical space), although a number of toddlers tried to carry them (e.g., Aida, FD.5).

\section{Curtain}

The musical curtain - consisting of metal plates, metal tubes, and bamboo rods hung from the ceiling - attracted much attention from our toddlers. The metallic part of the curtain was particularly rich in sound. The curtain afforded diverse gestures where the whole body could be used in different ways. Pablo and Antonio (FD.12), for example, used the spaces between the 
THE ACTIVE MUSICAL ROOM

curtain and the wall as a corridor to go through. Lucas (FD.11) and Clara (FD.2) laid down to create sounds with the curtain by kicking it. Many toddlers used drumsticks (FD.8) and beans to play with the curtain — one of the most common ways of interaction was to grab the curtain with the arms and then release it (Pablo, FD.7). In a sense, as these examples show, the curtain was explored more in terms of physicality than sonority. When sounds were created, these were more related to the unpredictable movements of the curtain, rather than the controlled action of the toddler. The level of motor control required for the curtain to be musically explored, therefore, was probably beyond the toddlers' ability. Additionally, the curtain was undoubtedly one of the objects involving greater risks. The launching of the curtain's metal plates, for example, was dangerous, especially for Pablo, who was almost always close to them. The teacher had to act on several occasions to avoid accidents.

Despite what we expected given the physical shape and size of the curtain, this object did not afford much social interaction. Toddlers explored the curtain in different ways, but mostly alone. One of the toddlers with special needs, Pablo, was really interested in the curtain. He approached it in all his sessions and engaged with it in various ways to generate different sounds. The CA team told the family about his passion and his parents decided to install a new curtain at home, just like the one used in the AMR (TI.2). Pablo's parents, indeed, valued musical engagement highly (QP.13) and wanted to help stimulate their son's musicality in this way.

\section{Scraper}

The scraper was not very attractive to our toddlers at first. However, it was one of the objects, along with beans and nuts, that eventually fostered more intense social moments. An example is the interaction between Lucas, Manuel, and Pedro (see social interaction section, below). The 


\section{THE ACTIVE MUSICAL ROOM}

scraper is not an invasive tool-it is handy, relatively small, and does not produce loud sounds. However, it facilitated social exchanges more than other objects. In terms of exploration, toddlers scraped (FD.6), shook (FD.9), hit (FD.8), held and let it down, and inserted the drumstick in the slot of the scraper (FD.8). Some toddlers also combined the scraper with tiles or with nuts in order to create more complex instruments. There was a session (FD.10) in which Lucas made musical patterns combining scraping and hitting the tiles and the nuts bowl. Social interaction with the scraper required adaptation and collaboration due to space constraints. Consider for example a session where Manuel and Lucas were playing together (using both hands) with the scraper; in order to let another toddler (Pedro) join in, they started playing with just one hand. Here toddlers privileged a social situation to optimize and augment their musical and exploratory experience (FD.10).

\section{Bamboo Leaves}

The bamboo leaves, due to their sonic characteristics, did not have as much sound potential as the beans or the curtains. Consequently, the toddlers explored them very little. They were interested in their tactile or visual properties, rather than their sonic ones. Some of the affordances this object provided included throwing the leaves (FD.10) or breaking the leaves (FD.9). The teacher used the bamboo leaves for relational purposes to caress a toddler, as she did with Daniel (FD.9). For this reason, the teacher believed that the bamboo leaves should be presented to the toddlers in isolation of other objects to allow for proper exploration (IT.1). 
THE ACTIVE MUSICAL ROOM

\section{Toddlers' Perspectives: Learning in the AMR}

The objects described in the previous section, along with their affordances, became an integrative part of the toddlers' various learning trajectories. They were, so to speak, incorporated in the activity of the toddlers when an appropriate action was mastered adequately. That is, when the goal of the action becames the sound itself rather than the sensorimotor engagement with the object, a process known as teleomusical development began to occur (Schiavio et al., 2017). Within this complex interplay of sounds, objects, and actions, three critical aspects were identified: a process that led from exploration to creation; the individually meaningful (or inclusive) features of the objects; and the social interactions that emerged in the process of discovery.

\section{Processes: From Exploration to Creation}

According to Delalande, infants, toddlers, and children of different ages can spontaneously develop sophisticated ways of engaging with the sonic affordances of their environment (Delalande et al., 2001). This involves three distinct phases, which also emerged from our data.

Exploratory Phase. Toddlers generally started their exploration with the objects they considered relatively more attractive. At the beginning, these were the curtain and the tambourine with beans, but little by little, other objects were included. The word cloud generated in atlas.ti showed an interest for curtain and tambourine (FD.1-5) within the first sessions, and then for nuts (FD.6), the curtain (FD.7), and scraper (FD.9) later on. This initial exploratory phase was characterized by a rich variety of goal-directed actions such as pulling, throwing, emptying, breaking, or rubbing one of the objects. Another clear example of exploration, where new motor possibilities emerged, included touching an object with parts of the body unexplored up to that 


\section{THE ACTIVE MUSICAL ROOM}

moment (e.g., touching with the feet, swimming among the beans), or moving objects to other places such as when Lucas relocated the tiles or the bowl of nuts near the scraper to build complex instruments (FD.10).

Semantic Phase. When the toddlers explored the AMR, they initially tended to focus on one object and afterwards explored it deeper. Clara, for example, displayed different ways of exploring the sound possibilities of the nuts (FD.11). Pablo, instead, was fascinated by the curtains, and every day he went directly to it without any reinforcement from the teacher. The semantic phase is characterized by subtler gestures and greater listening capacity. The toddlers performed an action and then analyzed the sonic consequences of the actions, i.e., what sounds were being produced and how could they be elaborated upon. Here the focus was shifted towards the goal of the action rather than the object. Consider how Claudia played the curtain of tubes with the drumstick softly while singing (FD.9) or how played the tube and grabbed it while saying "it sounds different" (TI.1).

Creative Phase. The third phase proposed by Delalande, the creative one, was hardly observed. This may have been due to the briefness of the workshop and the age of the participants. For example, the teacher once reported that "only Pedro has begun to create" (TI.1). The main features of the creative phase include repetition, narrativity, structure, dialogue, and the capacity to elaborate and further develop previous learning. In a sequence of interaction among three toddlers (i.e., Manuel, Pedro and Lucas), many of these features were observed (FD.10).

There is an interaction between the three with different actions: Manuel leads the rhythmic leadership with alternating scrapes with stick and hand (sometimes with two drumsticks). Lucas and Pedro are added in alternative scrapes. Lucas sometimes 
THE ACTIVE MUSICAL ROOM

scratches with his hand too. Pedro alternates scraping with shaking nuts or hitting the bowl. (FD.10)

The teacher believed that each toddler followed their own personal development and achieved goals at their own pace. Every toddler, therefore, went through the exploratory phase interacting with all the objects, but only some of the older ones moved on to the semantic phase (TI.1). The age of our participants could then explain why all phases proposed by Delalande were not equally observed in our study, since engagement in the creative phase tends to arise when toddlers get older (Céleste \& Delalande, 1997; Dansereau, 2015; Glover, 2000). Moreover, depending on what notion of creativity one embraces and what one emphasizes when studying creative processes, different explanations of what creativity entails may emerge.

\section{Inclusion in the AMR: Individual needs}

The concept of inclusion does not refer exclusively to toddlers with special needs, but also to the diversity, maturation, and needs of every participant. The acknowledgment of individual identity is one of the cornerstones of the CA's pedagogical principles (IP.1). That being said, the robustness of an inclusive proposal can also be tested by analyzing the cases of participants with special needs. As mentioned earlier, there were two toddlers with special education needs at CA. Daniel has a rare condition that affects him in multiple ways. In the words of the teacher:

Daniel had little motor control but this leaded his exploration in a different way [...] he has to explore with the whole body, and therefore his exploration is different and the 


\section{THE ACTIVE MUSICAL ROOM}

sounds he gets are diverse too. I am not sure if more control allows better exploration, I think it just allows different exploration (TI.2).

Pablo, who has Down syndrome, discovered a passion for musical activity through the sonic exploration of curtains. As the teacher reported:

He got very angry when we asked him to leave. [...] He had a special connection with the curtains, from the first moment $[\ldots]$. He enjoyed throwing it and the way it came back [...]. Curtains go back and they produce sound. The sound made the difference for $\operatorname{him}(\mathrm{TI} 2)$.

In both cases, their inclusion in terms of presence, participation, and progress (Booth \& Ainscow, 2011) was considered satisfactory (IP). Their presence was higher than the group average (number of sessions they enter the AMR: group =4, Daniel = 5, Pablo =7). Regarding participation, they explored all six objects. Their progress was thus similar to their peers, as they went through the exploratory and semantic phases (only one participant reached the creative phase). From an inclusive point of view, exploration with these objects allowed the toddlers with special needs to develop at their own pace and discover new forms of interaction and creativity. The inclusiveness of the AMR is, perhaps, due to two possible reasons. On the one hand, objects did not need to be explored in a specific way, since they afforded a rich variety of behaviours. Indeed, depending on the motor possibilities of the agent, the affordances of objects will change. On the other hand, the objects themselves have their own constraints and can enhance learning in a number of ways; 
THE ACTIVE MUSICAL ROOM

stimulating interest, creativity, and sensorimotor discoveries. In other words, objects, just like teachers, are an integrative part of learning and the toddlers' development.

\section{Social Interaction: Learning from Others and With Others}

In general, toddlers primarily explored objects individually. However, they also demonstrated three types of exploratory social behavior: mutual observation, interaction, and collaborative play. Occasionally, they were inspired by observing other classmates interacting with the objects in different ways. They also interacted with each other to ask for something (drumsticks, for example) (Aida FD.10), or through sharing (e.g., the moving of nuts or beans that was almost always a collective activity) (FD.1, FD.4). Sometimes, working in collectively posed limitations or problems, but at other times it offered gains. Regarding limitations, counterproductive social exchanges sometimes occurred when several toddlers wanted to explore the same objects (TI.1). For other toddlers, social contact even seemed to hinder creative development such as was case for Aida: "When she is alone, she concentrates on small things better than being with other children" (TI.1). The contact among toddlers varied from session to session, which meant an everchanging environment that offered new opportunities and possibilities for (inter)action. As the teacher commented: 


\section{THE ACTIVE MUSICAL ROOM}

There is never a fixed group, never a similar workshop. If I go into the session with someone my interaction is different than if I go alone or with another person. All that makes you approach differently (TI.2) ${ }^{7}$.

Some toddlers, like Daniel, learned mainly by observing other classmates (TI.2). Others interacted at a musical level, as we have shown previously with Pedro, Lucas, and Manuel's interaction (DO.10). Other toddlers, such as Antonio, depended to a large extent on the approval of the adult, which also motivated him to try out objects (FD.1,2,5,8,10,15). With regard to this point, our teacher reported that:

He [Antonio] is one of the youngest toddlers. He has entered many sessions and has changed a lot. Antonio is very expressive and seeks a lot of response from adults [including newcomers], that made him trying a lot. What happens if I throw the beans? He pulls them and looks at you to see your answer. I do not know if it tests the sonority or the response of the adult (TI.1).

As such, the AMR became a social learning environment where toddlers shared a musically meaningful space in which affordances were negotiated as different sonic objects and actions were explored. As mentioned earlier, however, it should be noted that sometimes toddlers explored the AMR in a more independent fashion due to their age.

\footnotetext{
${ }^{7}$ There are two groups of toddlers who always were together. One is composed of Lucas, Pedro, and Manuel - they are very close friends and do many things together; another was Elsa and Sara (twins), who only attended one session together (FD.4).
} 
THE ACTIVE MUSICAL ROOM

\section{Discussion}

This case study addressed the implementation of a musical workshop based on principles of Delalande's Pedagogie musicale d'éveil in an early childhood education setting. Given the qualitative design of this study, conclusions should not be generalized beyond this context. Our interest, instead, was in understanding the complexity of the children's experiences in this particular program (Stake, 1995). Here the synergies and discrepancies between the pedagogical and contextual principles of CA and the specific requirements of Delalande's musical pedagogy have been reported. The AMR workshop incorporated many pedagogical ideas and emphasized the toddlers' freedom of exploration and the teacher's non-directive role. We organize the discussion of our findings according to three overarching topics: pedagogical decisions, material affordances, and sensorimotor learning in social contexts. We also draw upon embodied cognition as a framework for interpreting our findings and inspiring applications for future musical settings.

\section{Pedagogical Decisions}

The development of the toddlers' musicality was not the only goal of the workshop. General pedagogical decisions, such as attending to the toddlers' affective needs (Delalande \& Cornara, 2010), or avoiding physical damage, were also prioritized. These priorities were necessary, otherwise the school's principal would have been less likely to allow for the implementation of the AMR (IP.1). This resonates with what has been referred to as a classroom ecological paradigm (Doyle, 1983), which holds both, the structure of tasks as well as the structure of social relationships as central priorities. The teacher's pedagogical decisions and the musical goals she set were made in light of the personal and social needs of the toddlers, the spatial and material 


\section{THE ACTIVE MUSICAL ROOM}

constraints of the AMR, her personal musical experience, and her understanding of the toddlers' musicality.

This aligns with research that has shown how teachers can use their intuition to respond to complex situations with immediacy (Wright \& Kanellopoulos, 2010). In a series of informal postworkshop meetings, the teacher described her decision-making process to the research team. She mentioned that her intuitive decisions were informed by her understanding of the toddlers' characteristics as well as her view regarding how the principles of Delalande's musical pedagogy fit into the pedagogy of the CA. In a sense, therefore, the AMR involved a structural coupling among teacher, materials, and toddlers (Gluschankof, 2008). The workshop was shaped as it evolved in a given context, which is reminiscent of principles of embodied cognition (e.g., Varela et al., 1991).

\section{Material Affordances}

The six complex objects included in the AMR were varied enough to allow us to observe all the categories proposed by Delalande. The variability of the objects involved more than the differences in their physical characteristics. According to Gibson (1979), an organism does not perceive the inherent qualities of objects, but rather their affordances and affordances depend on what we can we do with these objects in a given context, our biological complexity, and our motor repertoire. Interestingly, our results were similar to those of previous researchers who found that musical achievement can help toddlers remain focused in prolonged exploratory activities (Céleste et al., 1982). The objects acquired forms of use, sonorities, limitations and diverse possibilities depending on the toddlers in the room and how their exploration unfolded (Krueger, 2014). Nevertheless, some objects showed sound-oriented potential (e.g., scraper) while others were more 
THE ACTIVE MUSICAL ROOM

likely to foster motor activity (e.g., curtain). In addition, social interactions were more likely to occur with certain objects (e.g., scraper, beans, nuts) while others were more often observed provoking individual introspection (e.g., curtain). Although toddlers often explore their sonic world autonomously (e.g., Schiavio et al., 2017), interactions with peers, caregivers, and groups are critical as well. Indeed, not all objects were examined at the same time in the same way, suggesting that affordances may have changed according to changes in context and that variety of the exploratory behaviors of the toddlers. As such, because of the toddlers' varied personal identities and motor awareness, the objects did not show constant characteristics over time. Their musical possibilities evolved as toddlers became familiar with them and as they shaped their personal musical journey through action, interaction, and the use of other objects. This kind of evolution was also documented by other scholars (e.g., Young, 2003) and has appeared in several instances of our results, where patterns of action, interaction, and material engagement were recursively transformed and developed as the workshop progressed over time.

\section{Sensorimotor Learning in Social Contexts}

The affordances that emerged from the interactions between objects, toddlers, and the music being created also facilitated the toddlers' musical learning and exploratory drive, helping them to find novel possibilities of collaborative learning. The findings of the current study demonstrate how active learning can play out in many different ways; through behavioral and operational norms, limits imposed by others, and connection and transformation of experiences (Hallam, 2010). The AMR offered a meaningful environment where interaction and freedom were prioritized over prescribed learning, and where intuition and creativity were fostered through minimal intervention from the teacher (Borgo, 2005). Interacting with some of the objects in the AMR was difficult for 


\section{THE ACTIVE MUSICAL ROOM}

some toddlers due to their young age and developing sensorimotor ability. As such, the potential for learning-through-action was somewhat limited for some children. However, the curiosity and drive to explore and play with the objects led the toddlers to reinforce existing motor behaviors and also stimulated the emergence of novel motor configurations.

In this sense, the relationship between action and sound in early childhood exploratory behavior can be viewed as a Janus-faced experience that involves what Høffding and Schiavio (2019) refer to as the dual intentionality of music-making. One intentionality is directed toward the external world and the music being created; and one is directed towards the self, that is, the mental and physical abilities that are developed and can further stimulate musical discoveries. This resonates with work by Peñalba (2011), who suggested that toddlers' exploratory musical activities might help them develop novel understandings of the world, and, recursively, self-awareness and higher-order consciousness (O’Regan \& Noë, 2001b, 2001a).

\section{Conclusion}

While generalizations cannot be proposed given the nature of the study, our results point to the recursive interplay between the exploratory drive of toddlers, their sensorimotor ability, and the constraints afforded by the environment in which they are situated (i.e., teachers, objects). As such, the AMR facilitated our understanding of musical development as a continuous adaptation to the affordances of children's surroundings.

In addition to the challenges identified in this case study, the stakeholders involved valued the AMR for the inclusive possibilities it offered (Lubet, 2009); for its contribution to the expressive development of the toddlers (Delalande, 2013); and for its compatibility with other 
THE ACTIVE MUSICAL ROOM

active and non-directive pedagogies endorsed in this educational setting. This brings us back to the various pedagogies based on creativity briefly examined above (e.g., Bond, 2018; Delalande et al., 2001; Dennis, 1975; Paynter \& Aston, 1970; Schafer, 1969, 1976). Focusing on the range of needs and interests of young learners, these pedagogical approaches offer an ideal platform to help infants, toddlers, and children to flourish as musical beings. As we saw, settings involving musical materials and sound-producing objects can enhance the natural inclinations and exploratory drive of toddlers, in turn stimulating a curiosity for movements, sounds, and their complex interactions (Céleste, et al., 1982; Dansereau, 2015; Delalande 2015). We suggest that an early music pedagogy based on creative discovery may be highly beneficial for musical development and skill acquisition and can involve more than the directed activities that might be typical in many schools. We thus hope this preliminary study can inspire novel interventions and workshops aimed at fostering creative musical actions and interactions among infants and toddlers.

\section{Acknowledgments}

We thank Casa Activa and all participants who took part in the study. We are thankful to Don Oxtoby, who proofread the manuscript. AS is supported by the Austrian Science Fund (FWF): project number P 32460 . 


\section{THE ACTIVE MUSICAL ROOM}

\section{References}

Addessi, A. R., Maffioli, M., \& Anelli, F. (2015). The MIROR platform for young children's music and dance creativity. Reflexive interaction meets body-gesture, embodied cognition, and Laban educational dance. Perspectives, 10, 9-18.

Bond, V. L. (2015). Created in Context: A Comparative Case Study of the Use of Music in Two Reggio Emilia-Inspired Schools. Early Childhood Education Journal, 43(2), 119-126. https://doi.org/10.1007/s10643-014-0639-4

Bond, V. L. (2015). Sounds to Share: The State of Music Education in Three Reggio Emilia-Inspired North American Preschools. Journal of Research in Music Education, 62(4), 462-484. https://doi.org/10.1177/0022429414555017

Bond, V. L. (2018). Finding One's Place: A Case Study of a Music Atelierista. Journal of Research in Childhood Education, 32(2), 150-164. https://doi.org/10.1080/02568543.2017.1416005

Booth, T., \& Ainscow, M. (2011). Index for inclusion. Developing learning and participation in schools. (CSIE, Ed.) (3º. Bristol.

Chemero, A. (2009). Radical embodied cognitive science. MIT Press.

Céleste, B., Delalande, F., \& Dumaurier, E. (1982). L'enfant 12 du sonore au musical. Buchet/Chastel.

Céleste, B., \& Delalande, F. (1997). Productions Non Verbales dans les Jeux de Fiction. L'enfant du Sonore au Musical. Buchet/Chastel.

Clarke, E. F. (2005). Ways of Listening: an Ecological Approach to the Perception of Musical Meaning. Oxford University Press.

Cox, A. (2017). Music and Embodied Cognition: Listening, Moving, Feeling and Thinking. Indiana University Press.

Dansereau, D. R. (2015). Young children's interactions with sound-producing objects. Journal of Research in Music Education, 63(1), 28-46.

https://doi.org/10.1177/0022429415574001 
THE ACTIVE MUSICAL ROOM

Delalande, F. (ed.). (2009). La Nascita Della Musica. Esplorazioni Sonore nella Prima Infanzia. Franco Angeli.

Delalande, F. (2013). Las conductas musicales. Ed. Universidad de Cantabria.

Delalande, F., \& Cornara, S. (2010). Sound explorations from the ages of 10 to 37 months: The ontogenesis of musical conducts. Music Education Research, 12(3), 257-268. https://doi.org/10.1080/14613808.2010.504812.

Delalande, F., Vidal, J., \& Reibel, G. (2001). La música es un juego de niños. Ricordi Americana. Deliège, I. \& Sloboda, J. (Eds.) (1996), Musical Beginnings: Origins and. Development of Musical Competence. Oxford University Press.

Dennis, B. (1975). Projects in sound. Universal Edition.

Denzin, N. K. (2001). Thick description. In Denzin, N. K. Applied Social Research Methods: Interpretive interactionism (pp. 99-118). SAGE Publications, Inc. https://dx.doi.org/10.4135/9781412984591.n6

Doyle, W. (1983). Academic work. Review of Educational Research, 53, 159-199. http://dx.doi.org/10.3102/00346543053002159

Einarsson, A. \& Ziemke, T. (2017) Exploring the Multi-Layered Affordances of Composing and Performing Interactive Music with Responsive Technologies. Frontiers in Psychology, 8:1701. https://doi.org/10.3389/fpsyg.2017.01701

Filippa, M. (2009). Exploring the sound of instruments in early infancy: finding something new and developing the musical idea, the amplification. In A.R. Addessi, \& S. Young (Eds.), Proceedings of the European Network of Music Educators and Researchers of Young Children (pp. 545-552). Bononia University Press.

Filippa, M., Lordier, L., De Almeida, J.S., Monaci, M.G., Adam-Darque, A., Grandjean, D., Kuhn, P. Hüppi, P. (2020). Early vocal contact and music in the NICU: new insights into preventive interventions. Pediatric Research, 87, 249-264. 


\section{THE ACTIVE MUSICAL ROOM}

https://doi.org/10.1038/s41390-019-0490-9

Flohr, J. W. (1985). Young children's improvisations: Emerging creative thought. Creative Child \& Adult Quarterly, 2, 79-85.

Gallagher, S. (2005). How the body shapes the mind. Oxford University Press.

Gerson, S. A., Schiavio, A., Timmers, R., \& Hunnius, S. (2015). Active drumming experience increases infants' sensitivity to audiovisual synchronicity during observed drumming actions. PLoS ONE, 10(6): e0130960. https://doi.org/10.1371/journal.pone.0130960.

Gibson, J. J. (1979). The ecological approach to visual perception. Houghton Mifflin.

Glover, J. (2000). Children Composing 4-14. Routledge Falmer. https://doi.org/10.4324/9780203134412

Gluschankof, C. (2008). Musical expressions in kindergarten: An inter-cultural study? Contemporary Issues in Early Childhood, 9(4), 317-327. https://doi.org/10.2304/ciec.2008.9.4.217

Gordon, E. E. (1993). The early childhood music curriculum : songs and chants without words. GIA.

Gordon, E. E. (1997). A music learning theory for newborn and young children. GIA.

Gratier, M. (2003). Expressive timing and interactional synchrony between mothers and infants: cultural similarities, cultural differences, and the immigration experience. Cogn. Dev. 18, 533-554. https://doi.org/10.1016/j.cogdev.2003.09.009

Gratier, M., \& Magnier, J. (2012). Sense and Synchrony: Infant Communication and Musical Improvisation. Intermediality, 19, 45-64. https://doi.org/10.7202/1012655ar

Guest, G., Namey, E. E., \& Mitchell, M. L. (2013). Participant Observation. In G. Guest, E. E. Namey, \& M. L. Mitchell (Eds.), Collecting Qualitative Data. A Field Manual for Applied Research (pp. 75112). Sage Publications Ltd. 
THE ACTIVE MUSICAL ROOM

Hallam, S. (2010). The power of music: Its impact on the intellectual, social and personal development of children and young people. International Journal of Music Education, 28(3), 269-289. https://doi.org/10.1177/0255761410370658

Hargreaves, D. (1986). The developmental psychology of music. Cambridge University Press.

Hargreaves, D., \& Lamont, A. (2017). The psychology of musical development. Cambridge University Press.

https://doi.org/10.1017/9781107281868

Høffding S., \& Schiavio, A. (2019). Exploratory expertise and the dual intentionality of music-making. Phenomenology and the Cognitive Sciences. Online first. https://doi.org/10.1007/s11097-019-09626-5

Johnson, M. (2007). The meaning of the body: Aesthetics of human understanding. University of Chicago Press.

Krueger, J. (2014). Affordances and the musically extended mind. Frontiers in Psychology, 4, 1-13. https://doi.org/10.3389/fpsyg.2013.01003

Krueger, J. (2013). Empathy, enaction, and shared musical experience: Evidence from infant cognition. In T. Cochrane, B. Fantini, and K. Scherer (Eds.). The Emotional Power of Music: Multidisciplinary Perspectives on Musical Arousal, Expression, and Social Control, (pp 177-196), Oxford University Press.

Leman, M. (2007). Embodied Music Cognition and Mediation Technology. MIT Press.

Loaiza, J. M. (2016). Musicking, embodiment and the participatory enaction of music: Outline and key points. Connection Science, 28, 410-422.

Lubet, A. (2009). The inclusion of music/the music of inclusion. International Journal of Inclusive Education, 13(7), 727-739. https://doi.org/10.1080/13603110903046010 McPherson, G. (ed.) (2006). The Child as Musician: A Handbook of Musical Development. Oxford 


\section{THE ACTIVE MUSICAL ROOM}

University Press.

Malloch, S., \& Trevarthen, C. (2018). The Human Nature of Music. Frontiers in Psychology, 9:1680. https://doi.org/10.3389/fpsyg.2018.01680

Malloch, S., Shoemark, H., Črnèec, R., Newnham, C., Paul, C., Prior, M., et al. (2012). Music therapy with hospitalized infants - the art and science of communicative musicality. Infant Mental Health Journal, 33, 386-399. https://doi.org/10.1002/imhj.21346

Menin, D. \& Schiavio, A. (2012). Rethinking musical affordances. AVANT, 3, 202-215.

Moorhead, G., \& Pond, D. (1978). Music of young children. Free use of instruments for musical growth. Pillsbury Foundation for Advancement of Music Education.

O’Regan, J. K., \& Noë, A. (2001a). A sensorimotor account of vision and visual consciousness.

Behavioral and Brain Sciences, 24(05), 939-973. https://doi.org/10.1017/S0140525X01000115

O'Regan, J. K., \& Noë, A. (2001b). What it is like to see: A sensorimotor theory of perceptual experience. Synthese, 129(1), 79-103.

https://doi.org/10.1023/A:1012699224677

Paynter, J., \& Aston, P. (1970). Sound and silence: classroom projects in creative music. The resources of music series, 2. Cambridge University Press.

Peñalba, A. (2011). Towards a theory of proprioception as a bodily basis for consciousness in music. In D. Clarke \& E. Clarke (Eds.), Music and consciousness: Philosophical, psychological, and cultural perspectives. (pp. 215-231). Oxford University Press.

Phillips-Silver, J. \& Trainor, L.J. (2005). Feeling the beat: movement influences infant rhythm perception. Science, 308, 1430. https://doi.org/10.1126/science.1110922 
THE ACTIVE MUSICAL ROOM

Schaeffer, P. (1966). Traité des objets musicaux: essai interdisciplines. Paperback.

Schafer, R. M. (1969). The new soundscape. Din Mills BMI Canada Limited.

Schafer, R. M. (1976). Creative music education: A handbook for the modern music teacher. Schirmer Books.

Schiavio, A., van der Schyff, D. (2016). Beyond musical qualia: Reflecting on the concept of experience. Psychomusicology, 26(4), 366-378. http://dx.doi.org/10.1037/pmu0000165

Schiavio, A., \& van der Schyff, D. (2018). 4E music pedagogy and the principles of self-organization. Behavioral Sciences, 8(8), 72. https://doi.org/10.3390/bs8080072

Schiavio, A., van der Schyff, D., Kruse-Weber, S. \& Timmers, R. (2017). When the sound becomes the goal: 4E cognition and teleomusicality in early infancy. Frontiers in Psychology, 8:1585. https://doi.org/10.3389/fpsyg.2017.01585

Soley, G. \& Hannon, E. (2010). Infants prefer the musical meter of their own culture: a cross-cultural comparison. Developmental Psychology, 46, 286-292. https://doi.org/10.1037/a0017555

Stake, R. (1995). The art of case study research. Sage.

Strauss, A., \& Corbin, J. M. (1990). Open coding. In Basics of qualitative research: grounded theory procedures and techniques (pp. 101-121). Sage Publications Ltd.

Tafuri, J. (2017). Building musical self-identity in early infancy. In R. A. R. MacDonald, D. J. Hargreaves, \& D. E. Miell (Eds.). Handbook of musical identities (pp. 197-212). Oxford University Press.

Thompson, E. (2007). Mind in life: Biology, phenomenology, and the sciences of mind. Harvard University Press.

Trainor, L. J., Marie, C., Gerry, D., Whiskin, E. \& Unrau, A. (2012). Becoming musically enculturated: 


\section{THE ACTIVE MUSICAL ROOM}

effects of music classes for infants on brain and behavior. Annals of the New York Academy of Sciences, 1252: 129-138.

https://doi.org/10.1111/j.1749-6632.2012.06462.x

Trehub, S. E. (2003a). The developmental origins of musicality. Nature Neuroscience, 6, 669-673. https://doi.org/10.1038/nn1084

Trehub, S. E. (2003b). Musical predispositions in infancy: an update. In R. Zatorre and I. Peretz (Eds). The Cognitive Neuroscience of Music (pp. 3-20). Oxford University Press.

Trevarthen, C. (1999). Musicality and the intrinsic motive pulse: evidence from human psychobiology and infant communication. Musicae Scientiae, 3, 155-215.

https://doi.org/10.1177/10298649000030S109

van der Schyff, D., Schiavio, A., \& Elliott, D. (2016). Critical ontology for an enactive music pedagogy. Action, Criticism \& Theory for Music Education, 15(5), 81-121.

https://doi.org/10.22176/act15.5.81

van der Schyff, D., Schiavio, A., Walton, A., Velardo, V., \& Chemero, T. (2018). Musical creativity and the embodied mind. Exploring the possibilities of 4E cognition and dynamical systems theory. Music \& Science, 1.

https://doi.org/10.1177/2059204318792319

Varela, F. J., Thompson, E., \& Rosch, E. (1991). The Embodied Mind: Cognitive Science and Human Experience. MIT Press.

Wright, R., \& Kanellopoulos, P. (2010). Informal music learning, improvisation and teacher education. British Journal of Music Education, 27(01), 71.

https://doi.org/10.1017/S0265051709990210

Young, S. (2003). Music with the Under Fours. Routledge.

Young, S. (2018). Critical New Perspectives in Early Childhood Music. Routledge.

Zentner, M., Eerola, T. (2010). Rhythmic engagement with music in infancy. Proceedings of the National 
THE ACTIVE MUSICAL ROOM

Academy of Sciences, 107, 5568-5573.

https://doi.org/10.1177/0022429414555984

Zentner, M., \& Kagan, J. (1996). Perception of music by infants. Nature, 383(29).

https://doi.org/10.1038/383029a0 
THE ACTIVE MUSICAL ROOM

Table 1

A Description of the AMR Objects According to Delalande's Pedagogical Categories

\begin{tabular}{|c|c|c|c|c|c|c|}
\hline Name & Type & $\begin{array}{l}\text { Category } 1 \\
\text { Transportability }\end{array}$ & $\begin{array}{l}\text { Category } 2 \\
\text { Raw objects }\end{array}$ & $\begin{array}{l}\text { Category } 3 \\
\text { Brief/sustained }\end{array}$ & $\begin{array}{l}\text { Category } \mathbf{4} \\
\text { Controlled/Aleatory }\end{array}$ & $\begin{array}{l}\text { Category } \mathbf{5} \\
\text { Ways of interaction }\end{array}$ \\
\hline Scraper & $\begin{array}{l}\text { Wooden } \\
\text { tablecloth } \\
\text { composed of } \\
\text { sheets arranged } \\
\text { horizontally }\end{array}$ & $\begin{array}{l}\text { Non- } \\
\text { transportable }\end{array}$ & Wood & $\begin{array}{l}\text { Sustained } \\
\text { (iteration) } \\
\text { and Brief } \\
\text { (hitting, } \\
\text { oscillation) }\end{array}$ & Controlled & $\begin{array}{l}\text { Iteration } \\
\text { Shaking }\end{array}$ \\
\hline $\begin{array}{l}\text { Nuts on } \\
\text { glass }\end{array}$ & $\begin{array}{l}\text { Walnuts in a } \\
\text { raffia bag over } \\
\text { glass cup }\end{array}$ & Moving & $\begin{array}{l}\text { Nuts, } \\
\text { Cloth, } \\
\text { Glass }\end{array}$ & $\begin{array}{l}\text { Sustained } \\
\text { (accumulation) } \\
\text { and Brief } \\
\text { (idiophonic) }\end{array}$ & $\begin{array}{l}\text { Aleatory or } \\
\text { Controlled }\end{array}$ & $\begin{array}{l}\text { Bounding } \\
\text { Percussion } \\
\text { Accumulation }\end{array}$ \\
\hline $\begin{array}{l}\text { Beans in } \\
\text { tambour } \\
\text { ine }\end{array}$ & $\begin{array}{l}\text { Beans in a } \\
\text { leather } \\
\text { tambourine }\end{array}$ & Moving & $\begin{array}{l}\text { Seeds, leather, } \\
\text { wood }\end{array}$ & $\begin{array}{l}\text { Sustained } \\
\text { (iteration) } \\
\text { and Brief } \\
\text { (oscillation) }\end{array}$ & $\begin{array}{l}\text { Aleatory or } \\
\text { Controlled }\end{array}$ & $\begin{array}{l}\text { Rubbing } \\
\text { Percussion } \\
\text { Accumulation }\end{array}$ \\
\hline $\begin{array}{l}\text { Bamboo } \\
\text { leaves }\end{array}$ & $\begin{array}{l}\text { Bamboo leaves } \\
\text { on corrugated } \\
\text { wooden table }\end{array}$ & Moving & Wood, leaves & Brief & $\begin{array}{l}\text { Aleatory or } \\
\text { Controlled }\end{array}$ & $\begin{array}{l}\text { Accumulation } \\
\text { Percussion } \\
\text { Rubbing }\end{array}$ \\
\hline Tiles & Tiles & $\begin{array}{l}\text { Non- } \\
\text { transportable }\end{array}$ & Clay & Brief & Aleatory & $\begin{array}{l}\text { Oscillation } \\
\text { Percussion }\end{array}$ \\
\hline Curtain & $\begin{array}{l}\text { Pendant tubes } \\
\text { made of } \\
\text { cylindrical } \\
\text { metal, bamboo } \\
\text { rods and steel } \\
\text { plates }\end{array}$ & $\begin{array}{l}\text { Non- } \\
\text { transportable }\end{array}$ & $\begin{array}{l}\text { Metal, } \\
\text { wood }\end{array}$ & $\begin{array}{l}\text { Sustained } \\
\text { and Brief }\end{array}$ & $\begin{array}{l}\text { Aleatory or } \\
\text { Controlled }\end{array}$ & $\begin{array}{l}\text { Percussion } \\
\text { Iteration }\end{array}$ \\
\hline
\end{tabular}

Table 2

Summary of Data Sources and Labels

\begin{tabular}{lllc} 
Methods & Instruments & Label & $\begin{array}{c}\text { Number of sessions - } \\
\text { interviews -questionnaires }\end{array}$ \\
\hline Observation & Field diaries & FD & $1-15$ \\
& Observation template & OT & $1-15$ \\
& Video recordings & VR & $1-15$ \\
\hline Interviews & Teacher's interview & IT & $1-2$ \\
& Principal's interview & IP & 1 \\
\hline Questionnaires & Parents' questionnaires & QP & $1-17$ \\
\hline
\end{tabular}


THE ACTIVE MUSICAL ROOM

\section{Table 3}

Data Analysis Categories

\begin{tabular}{|c|c|c|}
\hline $\begin{array}{l}\text { Higher-order } \\
\text { Categories }\end{array}$ & Categories & Description \\
\hline \multirow{3}{*}{$\begin{array}{l}\text { Teacher's } \\
\text { perspective }\end{array}$} & Behaviour & Teacher's concerns regarding freedom and limits. \\
\hline & Affectivity & $\begin{array}{l}\text { Teacher's decisions regarding affectivity and safety concerns, particularly for } \\
\text { those in the adaptation period. }\end{array}$ \\
\hline & Experimentation & Teacher's encouragement of exploration of objects and creative process. \\
\hline \multirow{3}{*}{$\begin{array}{l}\text { Objects' } \\
\text { affordances }\end{array}$} & Physical features & Refers to the features of objects that attract toddlers. \\
\hline & Objects in context & Practicality of the use of objects within the specific context \\
\hline & Engagement & Gestural and sonic possibilities of each object. \\
\hline \multirow{3}{*}{$\begin{array}{l}\text { Toddlers' } \\
\text { perspective }\end{array}$} & Process & $\begin{array}{l}\text { Delalande's three phases of sound experimentation: sensorimotor, semantic, } \\
\text { and creative. }\end{array}$ \\
\hline & Inclusion & Possibilities of presence, participation and progress within AMR. \\
\hline & Social interaction & Observation of others, interaction with others, and collaborative play. \\
\hline
\end{tabular}

